\title{
Erken Çocukluk Döneminde Otizm Spektrum Bozukluğu Olan Çocuklarda Taklit Becerileri
}

\author{
Gökhan Töret ${ }^{*}$ \\ Gazi Üniversitesi
}

\author{
E. Rüya Özmen** \\ Gazi Üniversitesi
}

\begin{abstract}
Öz
Bu çalışmada erken çocukluk döneminde Otizm Spektrum Bozukluğu (OSB) olan çocukların taklit becerilerinin incelenmesi amaçlanmıştır. Çalışmada ilk olarak, taklit becerilerinin sınıflandırılması, taklitin işlevleri, taklit becerisinin gelişim evreleri sırası ile açıklanmıştır. Daha sonra OSB olan çocuklarda taklit becerilerinin gelişimsel seyri, taklit becerilerinin sergilenmesinde gözlenen sinırllıklar ilgili alan yazın doğrultusunda özetlenmiştir. Ayrıca, OSB olan çocuklarda taklit becerileri ile sosyal etkileşim becerileri ve dil ve iletişim becerileri arasındaki gelişimsel ilişki gözden geçirilmiştir. Son olarak da bu bulguların, OSB olan çocuklara taklit becerilerinin öğretimine yönelik yansımaları tartışılmıştır.
\end{abstract}

Anahtar Sözcükler: Otizm Spektrum Bozukluğu, sosyal etkileşim, taklit becerileri

\section{Abstract}

The purpose of this study was to examine imitation skills of children with Autism Spectrum Disorders (ASD) in early childhood period. Firstly, classification of imitation skills, functions of imitation, developmental stages of imitation skills are explained. Afterwards, developmental progress of imitation skills of children with ASD and their limitations in exhibiting imitation skills are summarized in line with the related literature. Moreover, the developmental relationship between imitation skills and social interaction skills and language and communication skills for children with ASD are reviewed. Lastly, reflections of these findings on teaching imitation skills to children with ASD are discussed.

Keywords: Autism Spectrum Disorders, social interaction, imitation skills.

Erken çocukluk döneminde, OSB olan çocuklarda taklit becerileri ile ilişkili araştırmaların ivme kazanması ile birlikte, taklit becerilerinin OSB olan çocukların dil, iletişim ve oyun, ortak dikkat gibi sosyal etkileşim becerilerinin gelişiminde önemli oranda rol oynadığı görülmektedir. Bu çalışmada, dil ve iletişim becerileri ve sosyal etkileşim becerileri açısından özgün bir profil sergileyen (Landa, 2007), OSB olan çocukların taklit becerilerinin incelenmesi amaçlanmıştır. Bu amaçla ilk olarak taklit becerilerinin sınıflandırılmasına, taklitin işlevine ve normal gelişim gösteren çocukların taklit gelişim evrelerine yer verilecek, daha sonra OSB olan çocukların taklit becerilerinde yaşadıkları sınırlılıklar ve taklit becerilerinin sosyal etkileşim ve dil becerileri ile ilişkisi ilgili alan yazın çerçevesinde betimlenecektir. Bulgular 1şı̆̆ında taklit becerileri öğretimine yönelik yansimalar siralanacaktır.

\footnotetext{
* Araş. Gör., Gazi Üniversitesi, Gazi Eğitim Fakültesi, Özel Eğitim Bölümü, Ankara, E-posta: gokhantoret@hotmail.com

** Prof. Dr., Gazi Üniversitesi, Gazi Eğitim Fakültesi, Özel Eğitim Bölümü, Ankara, E-posta: eruya@gazi.edu.tr Makale gönderim tarihi: 18.08.2014 Makale kabul tarihi: 13.12.2014
} 
Taklit, en yaygın tanımı ile başkası tarafından sergilenen bir davranış örneğinin, istekli biçimde tekrar üretilmesidir (Butterworth, 1999). Taklidin, kültürel farklılıklar olmaksızın (Wieland ve Stephan, 1978), erken dönemden itibaren insan gelişiminde, yeni davranışların edinilmesinde önemli bir rol oynadığı konusunda araştırmacılar arasında ortaya çıkan fikir birliği, alan yazında yaklaşık 40 yıl önce yerini almıştır (örn., Berry, 1974). Bunun yanı sıra gelişimsel yetersizliği olan çocukların da dâhil olduğu bireyler grubunda taklit; kuramsal ve kliniksel açıdan sosyal, nörolojik ve biyolojik bir olgu olarak karşımıza çıkmaktadır (Ham ve ark., 2011).

\section{Taklit Becerilerinin Sınıflandırılması}

Alanyazında, taklit becerileri türlerinin, gelişim ve öğrenme sürecindeki işlevi açısından farklı şekilde sınıflandırıldığı ve farklı taklit beceri türlerinin tanımlandığı görülmektedir. Taklit, sergilendiği vücut bölgeleri açısından; nesne, motor ve ses-sözel taklidi olarak sınıflanabilmektedir (Rogers, Young, Cook, Giolzatti ve Ozonoff, 2008). Bunlardan nesne taklitleri (object imitation), nesnenin anlamlı veya anlamlı olmayan kullanımını içeren bir eylemin taklit edilmesi olarak tanımlanmaktadır (Ingersoll ve Shreibman, 2006; Stone, Ousley ve Littleford, 1997). Bu tanımlamada belirtilen nesne ile ilişkili eylemlerin, işlevsel eylemlerin yanı sıra işlevsel olmayan eylemleri de içerebileceği belirtilmektedir (Zaghlawan, 2010). Bu bağlamda işlevsel eylemler, günlük rutin içerisinde, doğal ortamlarda bağlam içerisindeki etkinlikler veya nesneler ile ilişkili eylemleri ifade ederken (örneğin, arabayı ileri geri itme, bebeğin saçını tarama), işlevsel olmayan eylemler bağlam dışı olan etkinlikler veya nesnelerin kullanımı ile ilişkili olmayan eylemleri ifade etmektedir (örneğin, tarağı masa üzerinde gezdirme veya fincanı masa üzerinde itme (Stone ve ark., 1997). Anlamlı olan nesne taklit eylemleri gibi erken çocukluk döneminde görülen anlamlı olmayan taklit eylemleri, (Killen ve Uzgiris, 1981; McCabe ve Uzgiris, 1983), çocukların oyun becerileri ile yüksek düzeyde ilişki göstermektedir (Stone ve ark., 1997). Bilişsel ve sosyal işlevlere sahip karmaşık gelişimsel bir olgu olan (Stone ve ark., 1997) motor taklidi (motor imitation) ise iletişimsel amaçlı olarak kullanılan jestlerin (Ingersoll ve Lalonde, 2010), büyük ve küçük motor eylemlerin ve nesne gerektirmeyen vücut hareketlerinin taklidi (örneğin, el çırpma) olarak tanımlanmaktadır (Stone ve ark., 1997). Son olarak, ses taklidi veya sözel taklit (vocal imitation-verbal imitation) (Masur ve Olson, 2008) ise başkası tarafından üretilen iletişimsel amaçlı olan ya da olmayan sesletimlerin taklidi olarak betimlenmektedir (Rodgon ve Kurdek, 1977).

Taklidin sergilendiği vücut bölgesinin yanı sıra, alan yazında sergilenme süresi açısından anlık taklit, ertelenen taklit ve genellenen taklit olarak üç türde sınıflandırılmaktadır (örn., Zaghlawan, 2010). Bu taklit türlerinden anlık taklit (immediate imitation), başkası tarafindan sergilenen eylemin hemen sonrasında taklit edilmesi olarak betimlenirken (Nadel, Guérini, Pezé ve Rivet, 1999), ertelenen taklit (deferred imitation) daha önce başkası tarafından sergilenen bir davranışı taklit etme yeterliliği (Rogers ve ark., 2008) olarak tanımlanmıştır. Tipik olarak öğretimi yapılmaksızın ortaya çıkan (Meltzoff ve Moore, 1989) ve genişletilmiş bir taklit türü olan (Brown, Peace, Parsons, 2009) genellenen taklit ise (generalized imitation) başka bir taklit davranışının pekiştirilmesi yoluyla sürdürülen veya ortaya çıkan pekiştirilmeyen taklitsel tepki olarak kabul edilmektedir (Poulson, Kyparissos, Andreatos, Kymissis ve Marie Parnes, 2002).

Alan yazında hizmet ettiği işlev türüne göre de taklit becerileri sınıflandırılabilmektedir (Cardon, 2010). Bu sınıflamada, öğrenme işlevine hizmet eden stratejilerin taklit edilmesi ele alınmaktadır. Bu taklit becerileri türlerinden, hedef yönelimli taklit (goal-directed imitation) çocuğun sergilenen eylemlerden hedef içereni seçerek, taklit etmesi olarak adlandırılmaktadır. Yetişkinin yaptığı iki eylemden; oyuncak fareyi masa boyunca yürütmesi ve oyuncak masa boyunca yürüterek eve sokması eylemlerinden hedefe yönelimli olan maket eve sokma eylemini taklit etmesi, hedefe yönelimli taklite bir örnektir (Sakkalou, Ellis-Davies, Fowler, Hilbrink ve Gattis, 2013). Seçici taklit ise (selective imitation) hedefin gerçekleştirilmesi amaciyla modelin sergilediği eylemi seçerek, çocuğun eylemi sergilemesi olarak adlandırılır. İçinde oyuncak hayvan bulunan bir kutuda modelin oyuncak hayvanın çıkması için kutunun üstündeki düğmeye başı ile dokunması eylemini, çocuğun hayvanı çıkarmak için eliyle düğmeye dokunmak yerine başı ile dokunmayı tercih ederek taklit etmesi seçici taklide örnek olarak verilebilir (Seehagen ve Herbert, 2012). Rasyonel taklit ise (rational imitation) gözlenebilir hedefler, hedefe ulaşmada kullanılan yollar ve bu yolların kullanıldığı durumların taklit edilmesi olarak 
tanımlanmıştır. Model olunan basit bir materyalin nasıl çalıştığına ilişkin eylemin taklit edilmesi bir rasyonel taklit örneğidir (Zmyj, Daum ve Aschersleben, 2009). Son olarak, bilişsel taklit (cognitive imitation) model tarafından sunulan yeni bilişsel eylemlerin taklit edilmesi olarak adlandırılmaktadır. Benzer nesnelerin eşleştirilme eylemini taklit etme (Subiaul, Lurie, Romansky, Klein, Holmes ve Terrace, 2007) bilişsel taklite verilebilecek bir örnektir.

Tanımlamaları yapılan taklit becerileri türleri sınıflamalarına Şekil 1'de yer verilmiştir.

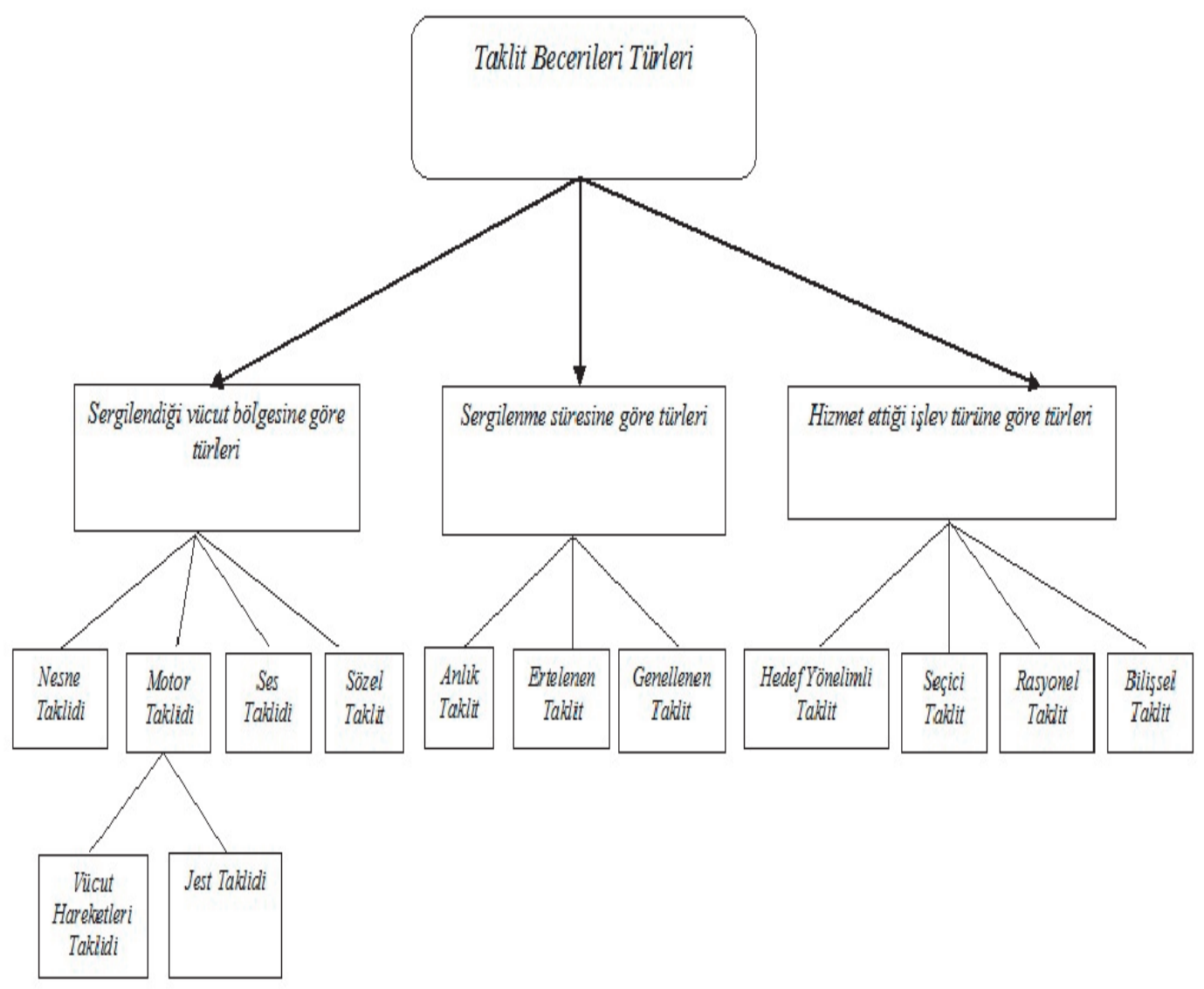

Şekil 1. Alan yazında tanımlamaları yapılan taklit becerileri türleri

Özetle, alan yazında farklı taklit beceri türlerinin tanımlandığı, bu taklit becerilerinin ise gelişim ve öğrenme sürecindeki işlevi açısından farklı biçimlerde sınıflandığı görülmektedir.

Taklidin erken dönemde dil ve iletişim, sosyal etkileşim ve bilişsel gelişimi alanı ile bağlantılı biçimde hizmet ettiği işlevlerinin belirlenmesinin, taklidin gelişim sürecinde oynadığı rolün daha iyi anlaşılması açısından önemli olduğu düşünülmektedir. Aşağıda, taklidin işlevleri alan yazına dayalı olarak açıklanmıştır. 


\section{Taklidin İșlevleri}

Erken çocukluk döneminde bulunan çocuklarda sosyal etkileşim becerilerinden biri olan taklidin, bebeklik döneminden itibaren etkileşim ortağı ile sosyal ve duygusal olarak iletişim alışverişine katılma açısından sosyal işlevi olduğu gibi (Ingersoll, 2008b; Ingersoll ve Lalonde, 2010), yeni beceri ve bilgileri edinmelerinde ögrenme işlevi de bulunmaktadır (Ingersoll, 2008a).

Sosyal işlevi açısından ele alındığında, taklidin bebek ile ebeveyn arasındaki ilk iletişim araçlarından biri olduğu belirtilmektedir (Turan ve Ö̉cçün-Akçamuş, 2013). Bu bağlamda, yaşamın ilk yılından itibaren bebeklerin çoğunlukla ebeveynleri olan birincil bakım verenleri ile iletişim kurmak amacıyla, amaçlı iletişim davranışları sergilediği bilinmektedir. Örneğin, bebek ve ebeveyn, karşılıklı olarak birbirine bakar ve birbirini dinlerken biri diğerinin ilgilerini, duygularını düzenler ve karşılıklı olarak ses, jest ve taklit alışverişinde bulunurlar (Paavola, 2006). Dolayısıyla, bebeklerin ebeveynleri ile olan yüz yüze etkileşimleri, anlık veya karşılıklı taklit ile ortaya çıkmaktadır. Bu etkileşim sürecinde, karşılıklı taklit oyunları, bebeklerin ebeveynleri ile sosyal ilgi bağlamında iletişim kurmasını sağlamaktadır (Ingersoll, 2008b). Ebeveyn ile çocuk arasındaki etkileşimin niteliği açısından taklidin, sosyal işlevine gelişimsel olarak bakıldığında, yaşamın ilk yılının sonlarına doğru, ebeveynleri ile arasındaki oyun etkileşimi bağlamında bebekler, yetişkinlerin oyuncaklar ile ilişkili eylemlerini de taklit etmeye başlar hale gelmektedir (Uzgiris, 1990). Yaşamın ikinci yılında ise bebek ile ebeveyn arasındaki taklit oyunları duygusal jestleri de içermeye başlamakta ve anne ile çocuk arasındaki etkileşimde taklit en sık kullanılan sosyal etkileşim araçlarından biri olmaktadır (Halliday ve Leslie, 1986).

Taklidin diğer bir işlevi ise öğrenme işlevidir (Uzgiris, 1999). Doğal ortamlarda, bebeklerin, yeni beceri ve davranışları öğrenmelerinde, başkalarının eylemlerini gözlemleyerek öğrenmeleri önemli bir yoldur (Barr ve Hayne, 2003). Bu doğrultuda taklit, çocuğun içinde bulunduğu fiziksel ve sosyal çevreyi keşfetmesi ve diğer insanların eylemlerinde amaçlananları öğrenmesi açısından, bir öğrenme aracı olarak hizmet etmektedir (Uzgiris, 1999; Barr ve Hayne, 2003). Ayrıca erken dönemde bilişsel gelişim sürecinde önemli bir rol oynayan taklidin (Metzoff, 1993), deneme ve yanılma ile problem çözme gibi öğrenme yollarına göre daha etkili bir öğrenme aracı işlevi görebildiği savunulmaktadır (Barr, Dowden ve Hayne, 1996). Taklidin gözleyerek öğrenme işlevi açısından önemli bir rol oynadığı görülmektedir. Bu bağlamda, gözleyerek öğrenmenin, model tarafından sergilenen bir davranışın gözlenmesi ile yeni davranışların edinimi olduğu bilinmektedir (Bandura, 1977). Ayrıca gözleyerek öğrenme, taklit becerileri gelişiminin hiyerarşik bir sırasını da yansıtmaktadır (Browder, Schoen ve Lentz, 1986). Bu doğrultuda, hiyerarşinin birinci basamağında, ayrık becerilerin öğretimsel ortamlarda taklidi yer alırken, ikinci aşamada, uyaran sunulmaksızın, öğretimsel ortamlar dışındaki ortamlarda taklidin kendiliğinden sergilenerek sürdürülmesi, son olarak üçüncü aşamada ise taklidin yeni davranışların öğrenilmesi için doğal ortamlarda kullanımı gelmektedir.

\section{Taklit Becerilerinin Gelişimi}

Taklit becerileri veya davranışlarının normal gelişim gösteren çocuklarda doğumdan itibaren başladığ görülmektedir. Bu bağlamda, bebeklerin henüz doğumdan birkaç hafta sonra ebeveynlerinin ses tonlamalarını ve ağız açıp kapama davranışlarını taklit etmeye başladıkları bilinmektedir (Meltzoff ve Moore, 1992). Sergilendiği vücut bölgesine göre taklit becerileri türleri normal gelişim gösteren bebeklerde 6-9 ay aralığında ortaya çıkmaktadır (Meltzoff, 1988). Bebeklerin taklit yeterliliğini incelemek amacıyla son yıllarda yapılan deneysel araştırmalarda, bebeklerin ebeveyn sesleri gibi iletişim davranışlarının yanı sıra ebeveynlerin veya diğer yetişkinlerin nesne ile ilişkili eylemlerini de taklit eden daha özel birer taklitçi olduklarını ortaya koymaktadır (Zymj ve ark., 2009). Bunun yanı sıra bebeklerin sergiledikleri taklit eyleminin modelin sergilediği eylemin basit bir tekrarı olmayıp seçici ve yorumlayıcı bir süreç olduğu da görülmektedir (Gergely, Bekkering ve Király, 2002). Bu bulguyu destekleyici nitelikte, 6-9 ayda bebeklerin taklit becerilerini inceleyen bir araştırmada bebeğin tanımadığı bir yetişkinin ve annenin sergilediği taklit eyleminden yetişkinin eylemini daha sık taklit ettikleri bulunmuştur (Seehagen ve Herbert, 2012). Buna ek olarak araştırmacılar klinik ve ev ortamında yaptıkları araştırmalarda fiziksel ve sosyal ortamın bebeklerin yeni davranışları öğrenmelerini etkileyebileceğini, 
ev ortamında yeni davranışları annelerinden öğrenebilmelerinin yanı sıra klinik ortamda yabancı bir kişinin anlamlı sayıdaki davranışını da gözleyerek öğrenebilecekleri sonucuna ulaşmışlardır (Ingersoll, 2008b). Diğer yandan, video görseli, sözel ipucu veya fiziksel ipucu sağlanarak sergilenen yapılandırılmış taklit eylemlerinin (Ingersoll, 2008a), 12. ayda ortaya çıktığı belirlenmiştir (Zmyj ve ark., 2009).

Taklit gelişiminde diğer bir bulgu ise 12. ay civarında bebeklerin, sosyal olarak kullanılan jestlere göre, nesne ve vokal eylemlerini daha fazla taklit etmesine yöneliktir (Heimann ve Ullstadius, 1999). 12-14 ay döneminde ise hedef yönelimli taklidin ortaya çıtığı görülmektedir (Carpenter, Call ve Tomasello, 2005; Sakkalou ve ark., 2013). Bunun yanı sıra, 12-14 ay döneminde rasyonel taklit eylemlerinin de gözlenmeye başlandığı belirtilmektedir (Zmyj ve ark., 2009). Taklidin gelişimi ile ilişkili olarak 14. ayda bebekler anlamsız eylemlere göre (örneğin, elini başına dokunma), daha fazla sıklıkta anlamlı eylemleri (örneğin, el sallama) taklit ederler. Ancak 22. ay civarında anlamlı eylemler ile anlamsız eylemlerin taklidi sıklık olarak dengeli biçimde sergilenir. Normal gelişim gösteren çocuklarda gözlenen taklit eylemleri, yaşamın ilk iki yılı boyunca gelişimini sürdürür (Meltzoff, 1988). 8, 14 ve 20. aylarda bebeklerin ses ve jest taklitlerini (örneğin, alkışlama) boylamsal olarak inceleyen Rodgon ve Kurdek (1977), ses ve jest taklitlerin üretiminin yaşla birlikte artış gösterdiğini, her bir yaş dönemi açısından jest taklitlerine oranla, ses taklitlerinin daha fazla kullanıldığını belirlemişlerdir. Diğer yandan, bebekler, 20. aya kadar yalnızca vücut hareketleri ile sergilenen eylemlerden daha çok, nesne ile ilişkili eylemleri (örneğin, arabayı masa boyunca ileri geri itme) taklit ederler (Stone ve ark., 1997). Daha yapılandırılmış koşullarda görsel hafıza veya eşleme/sınıflama yapma gibi bilişsel eylemlerin taklit edilmesini gerektiren bilişsel taklit eylemleri 24. ay civarında gözlenmektedir (Subjaul ve ark., 2007). 30. ay civarında ise taklit eylemlerinin kullanımının sürdürülmesi zirve yapmaktadır. 42-46 ay aralığında kendiliğinden (spontane) taklit kullanımının daha sık olarak kullanılması ile birlikte ayırt edici uyarana bağlı olarak ortaya çıkan taklit eylemlerinin kullanımında düşüş gözlenmektedir (Nadel, 2006). Erjavec ve Horne (2008), jest taklit eylemlerini sergilemeleri bakımından 2 ve 3 yaş döneminde olan 20 çocuğu boylamsal olarak incelemeleri sonucunda, 2 yaş döneminde, 3 yaş dönemine göre daha hatalı jest taklit eylemleri (örneğin, şarkı söylerken baş ve omuz hareketlerini daha az doğrulukta sergilenmesi) sergilediklerini ortaya koymuşlardır.

Çocukların ertelenen veya geciken taklit bakımından gelişimleri ele alındığında, 9-14 ay aralığında bulunan çocukların ertelenen veya geciken taklit performanslarında yaşla birlikte artış gözlendiği de belirlenmiştir (Heimann ve Meltzoff, 1996). Alan yazında ayrıca çocukların bulundukları ortamın taklit becerilerinin edinimi üzerindeki önemine vurgu yapılmıştır. Örneğin, Grusec ve Abramovich (1982), 2-5 yaş aralığında bulunan çocuklarda anlık taklidin çoğunlukla çocukların serbest oyun ortamında artış gösterdiğini belirlemişlerdir.

Taklit becerilerinin gelişimini inceleyen ilgili araştırmaların bulguları doğrultusunda, taklit gelişiminin doğumdan itibaren başladığı, yaşla birlikte taklit becerilerinin türlerinde ve sıklığında artış gözlendiği, doğumdan itibaren ebeveyn ile çocuk arasında iletişim alış verişi işlevi gören taklidin, erken çocukluk döneminin başlarında iletişim ile birlikte sosyal etkileşim ve öğrenme işlevi kazanmaya başladığı görülmektedir. Diğer yandan yapılandırılmış taklitten, kendiliğinden taklide doğru bir seyrin gözlendiği, taklit türleri açısından bakıldığında ise ses, nesneli ve motor taklit, hedefe yönelimli, rasyonel, eylemlerden jest taklidi eylemlerine, daha sonra da dil ve iletişim gelişimi ve diğer sosyal etkileşim becerilerinin gelişimi ile paralel olarak bilişsel taklit gibi karmaşık taklit becerileri türlerine doğru bir geçişin yaşandığı gözlenmektedir. Tüm bu incelemeler sonucunda, normal gelişim gösteren çocuklarda taklit becerilerinin gelişim aşamaları Şekil 2'de verilmişstir. 


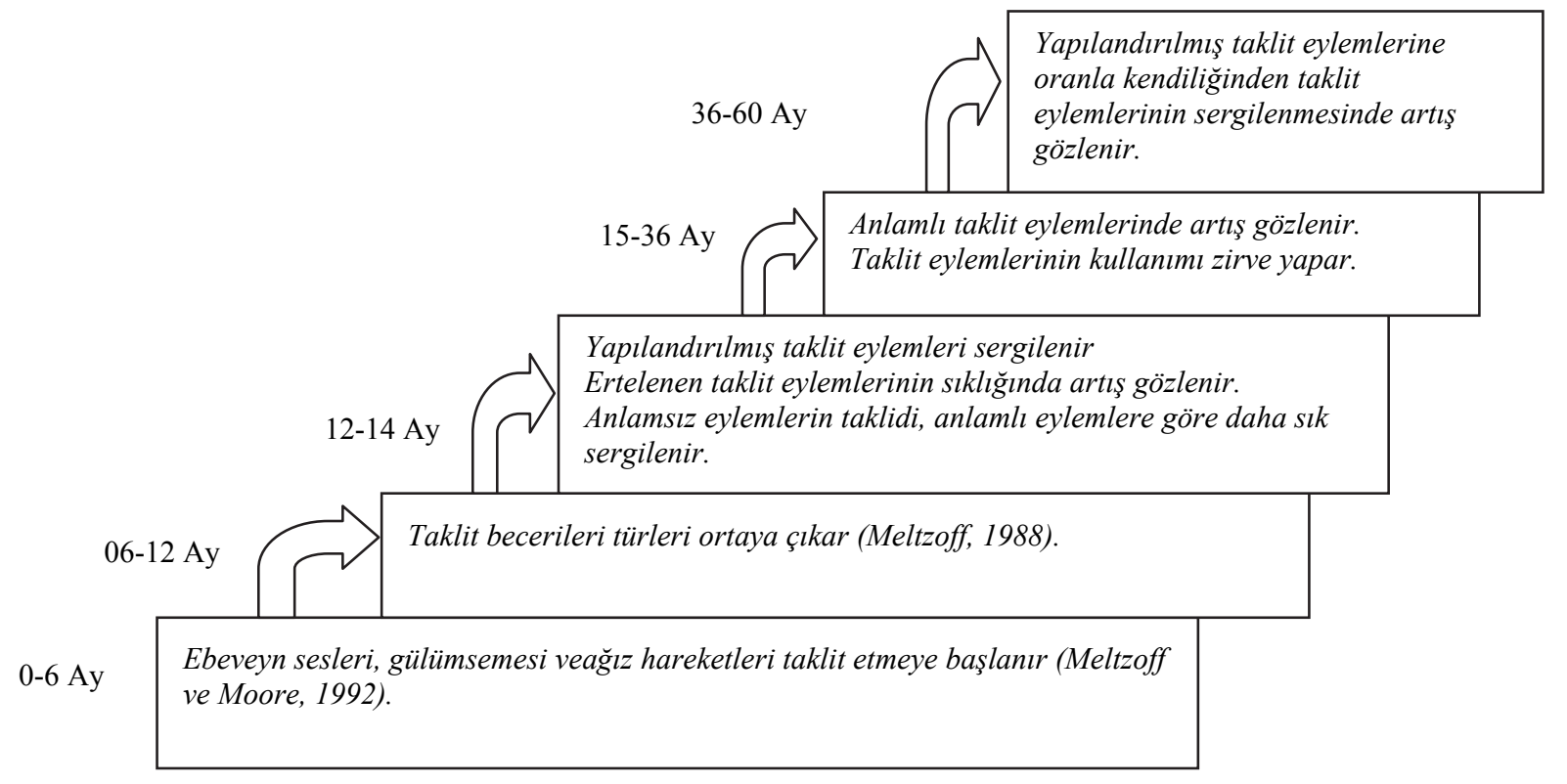

Şekil 2. Normal gelişim gösteren çocuklarda taklit gelişimi

Normal gelişim gösteren çocuklarda gözlenen taklit becerilerinin gelişim evreleri, OSB olan çocuklarda sergilenme türü ve sıklığı açısından sınırlılık göstermekte ve sıra dışı bir gelişim seyri izlemektedir. Aşağıda ilgili araştırmalar çerçevesinde OSB olan çocuklarda taklit gelişiminde görülen sınırlılıklar açıklanmıştır.

\section{OSB Olan Çocuklarda Taklit Becerileri}

OSB, erken dönemde ortaya çıkan, sosyal etkileşim ve sosyal iletişimde bozukluk, sosyal etkileşim ve toplumsal ilişki geliştirmede sorunlar, basmakalıp ve yineleyici davranışlar ile ilgi alanlarında sınırlılık olarak karakterize olan ve bu sınırlılıkların zihinsel yetersizlik veya gelişimsel gerilik ile açıklanamadığı bir bozukluktur (Amerikan Psikiyatri Birliği, 2013). OSB çocuklarda gözlenen sosyal etkileşim yetersizlikleri, OSB'nun ayırt edici tanı özelliklerinden biridir. Sosyal etkileşim becerilerinden biri olan taklit becerilerinin de (Ingersoll, 2008a), erken dönemden itibaren OSB olan çocuklarda sergilenme yeterliliğinin sınırlı olması, OSB tanısının ayırt edicilerinden biri olarak kabul edilmektedir (Lord ve ark., 2000). Erken dönemde daha şiddetli OSB semptomları gösteren çocuklar daha sınırlı düzeyde taklit becerileri sergilemektedir (Rogers, Hepburn, Stackhouse ve Wehner, 2003). Yetişkin ile çocuk arasında iki yönlü bir süreç olan karşılıklık (reciprocity) bağlamında (Gernsbacher, 2006), sosyal etkileşim yetersizliklerinin OSB olan çocukların taklit becerileri üzerinde olumsuz etkileri olabilmektedir (Ingersoll, 2008b).

OSB olan çocukların normal gelişim gösteren akranlarına oranla, daha sınırlı düzeyde taklit becerilerine sahip olduğu birçok çalışma sonucu göstermektedir (Charman ve ark., 1997; Curcio, 1978; Dawson, Meltzoff, Osterling ve Rinaldi, 1998; Heimann, Ullstadius, Dahlgren ve Gillberg, 1992; Ingersoll, 2008a; Libby, Powel, Messer ve Jordan, 1997; Rogers ve ark., 2003; Rogers ve Pennigton, 1991; Smith ve Bryson, 1994; Stone ve ark., 1997; Turan ve Ökçün-Akçamuş, 2013). İlgili araştırmalara bakıldığında, OSB olan çocukların, normal gelişim gösteren çocuklar (Charman ve ark., 1997; Rogers ve ark., 2003; Stone ve ark., 1997) ve gelişimsel düzeyi eşitlenmiş olan diğer gelişimsel yetersizlik gruplarında yer alan çocuklara göre (Heimann ve ark., 1992; Rogers ve ark., 2003; Stone ve ark., 1997) daha sınırlı düzeyde taklit becerileri sergiledikleri görülmektedir. 
Hem gelişimsel geriliği olan hem de OSB olan çocuklarda taklit becerileri sınırlılı̆̆ gözlenmesine rağmen, OSB olan çocuklarda gözlenen taklit becerileri sınırlılıklarının OSB'nun doğasına özgü bir sınırlılık olduğu savunulmaktadır (Rogers ve ark., 2003). Örneğin, benzer takvim yaşı, dil ve bilişsel düzeye sahip gelişimsel yetersizliği olan ve normal gelişim gösteren çocuklar ile OSB olan çocukların karşılaştırıldığı araştırmalarda (Bennetto, 1999; Bernabei, Fenton, Fabrizi, Camaioni ve Perucchini, 2003; Bernier, Dawson, Webb ve Murias, 2007; Dawson ve ark., 1998; Ohta, 1987; Rogers, Bennetto, McEvoy ve Pennington, 1996; Rogers ve ark., 2003; Smith ve Bryson, 1998), diğer gruplarda yer alan çocuklara göre OSB olan çocukların jest taklidi becerilerinin sınırlı olduğu ortaya koyulmuştur. Bu araştırmalarda elde edilen bulgular, jest taklidi becerileri sınırlılıklarının, OSB'nun doğasına özgü bir yetersizlik olduğunu destekleyici niteliktedir. Ayrıca, OSB'da taklit becerileri yetersizliklerinin altında yatan nedeni inceleyen çalışmalarda, eylemi sergileyen modele yöneltilen görsel dikkat güçlükleri (Rogers ve ark., 1996; Smith ve Bryson, 1998; Vivanti, Nadig, Ozonoff ve Rogers, 2008), eylemi sergileyen modelin izlenmesi açısından duyu-motor entegrasyonunu sağlayan ayna nöronları sınırlılıkları (Williams ve ark., 2006) ve taklit becerileri ile ilişkili olduğu belirlenen motor becerileri yetersizliklerinin (Canitano ve Vivanti, 2007; Dewey, Cantell ve Crawford, 2007; Ghaziuddin ve Butler, 1998) taklit sınırlılıklarının OSB'nın doğasına özgü olduğunu destekleyici bulgular olduğu vurgulanmıştır. Diğer yandan, OSB olan çocuklarda taklit becerileri yetersizliklerinin, erken dönemde OSB'na kısmen özgü olduğu yönünde bakış açıları da bulunmaktadır (örneğin, Vanvuchelen, Roeyers ve De Weerdt, 2010; Zachor, Ilanit ve Itzchak, 2010). Bu kısmi özgülük iki nedene bağlanmaktadır: a) alan yazında taklit becerileri ile otizmden etkilenme düzeyi ve motor becerileri yetersizlikleri gibi değişkenler arasında güçlü ilişki gösteren çalışmaların sınırlı olması, b) erken dönemde OSB olan çocuklarda gözlenen OSB semptomlarının oldukça çeşitlilik göstermesidir (Vanvuchelen, Roeyers ve De Weerdt, 2011). OSB olan çocuklarda taklit becerilerinde görülen sinırlılıklar OSB özgü ya da kısmen özgü olduğu görüşü olduğu savunulsa da araştırma verileri OSB olan çocukların taklit sinırlıklarını göstermektedir.

Yapılan araştırmalarda, OSB olan çocukların anlık ve geciktirilmiş taklit becerileri (Dawson ve ark., 1998), yüz ifadesi taklit becerileri (Loveland ve ark., 1994), nesneli ve nesneli olmayan taklit becerileri (Stone ve ark., 1997; Turan ve Ökçün-Akçamuş, 2013), jest taklitleri (Curcio, 1978; Smith ve Byrson, 1994; Stone ve ark., 1997), ve sembolik eylem taklitlerinde (Libby ve ark., 1997) gerilik gösterdikleri belirlenmiştir. Bunun yanı sıra, OSB olan çocukların motor taklidi becerilerinden el veya kol hareketleri ile sergilenen jestsel olmayan eylem taklidi becerilerinde (örneğin, iki elini masa üzerine vurma), jest taklidi becerilerine oranla (Stone ve ark., 1997), anlamlı olan jest taklidi becerilerinde, anlaml olmayan jest taklidi becerilerine oranla (Stone ve ark., 1997; Salowitz ve ark., 2013), daha yeterli oldukları sonucuna ulaşılmıştır. Nitel bir araştırmada ise Stone ve Lemanek (1990) normal gelişim gösteren akranları ile OSB olan ve gelişimsel geriliği olan çocukların etkileşimleri ebeveynleri tarafından gözlendiğinde, OSB olan çocukların ebeveynleri çocuklarının akranları ile olan etkileşimlerinde daha fazla taklit becerileri sınırlılıkları yaşadıklarını gözlediklerini bildirmişlerdir.

OSB olan çocuklarda taklit becerilerinin gelişimi ile ilgili araştırma bulgularına bakıldığında, dikkat çekici bir biçimde bu çocukların sosyal etkileşimsel ortamlarda taklit becerilerinin kendiliğinden kullanımında ciddi düzeyde yetersizliğe sahip oldukları görülmektedir. Ingersoll ve Gergans (2007) OSB olan çocukların taklit becerilerini doğal ortamlarda kendiliğinden kullanım düzeylerinin, yapılandırılmış taklit becerilerine oranla daha sınırlı düzeyde olduğunu belirlemişlerdir. Ingersoll (2008a) yedi normal gelişim gösteren çocuk ile yedi OSB olan çocuğun taklit becerileri edinim düzeylerinin yapılandırılmış ve kendiliğinden kullanım düzeylerine göre farklılaşıp farklılaşmadığının belirlemeyi amaçlamıştır. Araştırma sonucunda, gelişimsel yaş düzeyi kontrol altına alındığında, OSB olan çocukların normal gelişim gösteren akranlarına oranla, kendiliğginde taklit becerileri sınırlılıklarının, yapılandırılmış taklite oranla daha fazla olduğu ve taklit becerilerini sergilerken, daha az ortak dikkat davranışları sergiledikleri bulmuştur. Benzer olarak diğer bir araştırmada ise Ingersoll ve Meyer (2011b) 2 ve 4 yaşlarında bulunan (27-47 ay) 23 OSB olan çocuğun sosyal etkileşim ve iletişim becerilerini edinim düzeylerini, yapılandırılmış ve kendiliğinden taklit becerileri kullanım düzeyleri açısından boylamsal ve ilişkisel 
olarak incelemişlerdir. Araştırma sonucunda, OSB olan çocukların dikkati izleme ve oyun becerileri gibi sosyal etkileşimsel becerilerine oranla, yapılandırılmış taklit becerilerinde daha az sınırlılık gösterdikleri belirlenmiştir. Bunun yanı sıra, bu araştırmanın ilişkisel bulguları yapılandırılmış taklit becerilerinin, sözcük dağarcığı ile ilişkili olduğunu, kendiliğinden sergilenen taklit becerilerinin ise sözcük dağarcığı, sosyal karşılıklılık ve sembolik oyun ile ilişsili olduğunu göstermiştir. Sonuç olarak, OSB olan çocukların erken dönemden itibaren, taklit becerilerinde ciddi düzeyde yetersizlikleri içermekte olup, taklit becerileri türlerinden nesne taklidine oranla jest taklidinin sergilenmesinde daha fazla güçlük yaşadıkları görülmektedir. Bunun yanı sıra, yapılandırılmış taklit becerilerine göre kendiliğinden sergilenmesinde daha ciddi düzeyde güçlük yaşadıkları yönünde alan yazından elde edilen bulgular dikkat çekicidir.

\section{OSB Olan Çocuklarda Taklit Becerilerinin Sosyal Etkileșim ve Dil Becerileri ile İlişkisi}

Normal gelişim gösteren çocuklarda olduğu gibi taklit, OSB olan çocuklarda bilişsel, sosyal, dil ve iletişim becerilerin gelişiminde önemli rol oynamaktadır (Ingersoll, 2008a). Taklidin OSB olan çocuklarda dil (Bates, Bretherton ve Snyder, 1988), oyun (Fiese, 1990) ve ortak dikkat becerileri ile ilişkili olduğu bilinmektedir (Carpenter, Nagell ve Tomasello, 1998). OSB olan çocuklar ile yürütülen ilgili araştırmalara bakıldığında, taklit becerilerinin, eş zamanlı olarak dil becerileri ve (Bates ve ark., 1988; Carpenter, Pennigton ve Rogers, 2002; Charman ve ark., 2003; Luyster, Kadlec, Carter ve Tager-Flusberg, 2008; Stone ve ark., 1997; Toth, Munson, Meltzoff ve Dawson, 2006; Turan ve Ökçün-Akçamuş, 2013) oyun becerileri ile (Stone ve ark., 1997; Toth ve ark., 2006) ilişkili olduğu bulunmuştur. Ayrıca, taklidin dil öncesi iletişim becerileri ile ilişkisi açısından değerlendirildiğinde, Curcia (1978) jest taklidinin, sözel iletişime sahip olmayan OSB olan çocukların kullandığı iletişimsel jestlerin sayısı ile iliş̧kili olduğunu belirlemiştir.

OSB olan çocuklarda taklidin dil ve iletişim becerileri ve diğer sosyal etkileşimsel becerileri arasındaki boylamsal yöndeki gelişim ilişkisi dikkati çekmektedir. OSB olan çocuklar ile yürütülen ilgili araştırmalara bakıldığında, örneğin, vücut hareketleri taklitinin 6 ay sonraki ifade edici dil gelişiminin yordayıcısı olduğu belirlenmiş̧tir (Stone ve ark., 1997). Stone ve Yoder (2001) ise 2 ve 4 yaşlarında bulunan 35 çocuğun motor taklit yeterliliği ile dil becerilerini değerlendirmeleri sonucunda, motor taklit yeterliliğinin 4 yaşındaki dil kazanımlarını anlamlı olarak yordadığını belirlemişlerdir. Stone ve arkadaşları (1997), 2 yaş döneminde nesne taklidi becerileri ile bir yıl sonraki oyun becerileri arasında yüksek düzeyde ilişki olduğunu belirleyerek, oyun gelişiminde taklit becerisinin önemli rol oynadığını belirtmişlerdir.

Taklidi bütün bir boyut olarak ele alan araştırmaların yanı sıra taklidin farklı türlerini bağımsız bir birim olarak ele alan, sosyal etkileşim ve dil becerileri ile ilişkisini belirleyen araştırmalar da bulunmaktadır. $\mathrm{Bu}$ araştırmalarda taklidin alt boyutlarında yer alan taklit becerileri türlerinin dil, ortak dikkat ve oyun becerileri ile farklı düzeylerde ilişkili olduğu ortaya koyulmuştur (örn., Ingersoll ve Meyer, 2011b; McDuffie ve ark., 2007; Rogers ve ark.,, 2003; Stone ve ark., 1997). Bu bağlamda, araştırmalar sonucunda elde edilen farklı bulgular, taklit becerilerinin alt boyutlarının diğer gelişim alanları ile ilişkisinin değerlendirilmesinde ayrı bir boyut veya taklidin bütün bir boyut olarak ele alınması tartı̧malarını da ortaya çıkarmıştır (Ingersoll ve Meyer, 2011a).

Stone ve arkadaşları (1997) ise OSB olan çocuklarda nesne ve vücut hareketi taklitlerinin birbirleri ile ilişkili olmadığını ortaya koyarak, taklidin farklı türlerinin bağımsız bir birim olarak temsil edilebileceğini belirtmiştir. Bu doğrultuda, Stone ve arkadaşları (1997) nesne taklidi becerilerinin oyun becerilerinin; vücut hareketleri taklidinin ise dil becerilerinin en güçlü yordayıcısı olduğunu belirlemişlerdir. Stone ve arkadaşlarının bulgularının aksine Rogers ve arkadaşları (2003) farklı bulgular elde ederek, nesne taklidi ile sözel taklit eylemlerinin birbirleri ile yüksek düzeyde ilişkili olduğunu belirlemişlerdir. McDuffie ve arkadaşları (2007) ise Stone ve arkadaşlarının (1997) bulgularını destekleyecek nitelikte bulgulara ulaşmışlar; nesne taklidi becerileri kontrol altına alındığında vücut hareketleri taklidinin dil üretiminin en güçlü yordayıcısı olduğunu belirlemişlerdir. Toth ve arkadaşları (2006) ise aynı şekilde Stone ve arkadaşlarının bulgularına benzer olarak 
gelişimsel düzey kontrol altına alındığında, nesne taklidi becerilerinin hem işlevsel oyun hem de sembolik oyun ile ilişkili olduğunu belirlemişlerdir. Ingersoll ve Meyer (2011a) ise nesne taklidi becerisinin oyun becerileri ile jest taklidinin, ifade edici dil becerileri ile ilişkili olduğunu ortaya koymuşlardır. Sonuç olarak nesne taklidinin oyun becerileri ile jest taklidinin ise dil becerileri ile ilişkili olduğu yönünde daha fazla araştırma bulguları bulunmaktadır.

Diğer yandan, istatistiksel açıdan güçlü bir ilişkiden söz edilemese de taklit ile sosyal etkileşim becerilerinden biri olan ortak dikkatin ilişkili olduğu yönünde bulgulara da ulaşılmıştır. Örneğin, Carpenter ve arkadaşları (2002), nesne taklidi ve koordineli bir ortak dikkatin, okul öncesi dönemdeki OSB olan çocuklarda birbirleri ile ilişkili olduğunu ortaya koymuşlardır. Ayrıca, nesne taklidinin, ortak dikkat gelişiminin anlamlı bir yordayıcısı olduğu bulunmuştur (Carpenter ve ark., 1998). Özetle ilgili araştırmalar, taklit becerilerinin dil ve iletişim becerileri ve diğer sosyal etkileşim becerileri olan ortak dikkat ve oyun becerileri ile eş zamanlı ve boylamsal olarak ilişkili olduğunu ortaya koymaktadır. OSB olan çocuklarda taklit becerilerinin dil ve iletişim ve sosyal etkileşim becerileri ile olumlu yönde gösterdiği ilişki düzeyi, taklit becerileri müdahalelerine yönelik yapılan araştırmalarda da incelenmiştir. Son yıllarda taklit becerileri öğretimi amacıyla geliştirilen müdahale programlarının, dil ve iletişim ile diğer sosyal etkileşim becerilerinin edinim ve kendiliğinden kullanım düzeylerinde artışla sonuçlandığı görülmektedir. İlgili araştırmalarda taklit becerileri öğretimine yönelik müdahale programlarının uygulanması sonucunda OSB olan çocukların, dil (Ingersoll ve Shriebman, 2006), oyun (Ingersoll ve Shriebman, 2006; Ingersoll, 2010) sosyal kattlim (Ingersoll ve Shriebman, 2006; Ingersoll ve Gergans, 2007; Walton ve Ingersoll, 2012), jest kullanım düzeyi (Ingersoll, Lewis ve Kroman, 2007), bağlama uygun dil kullanım düzeyi (Ingersoll ve Lalonde, 2010), ortak dikkat ve sosyal-duygusal gelişim düzeylerinde (Ingersoll, 2012) artış gözlenmiştir. Örneğin, Ingersoll ve Shreibman (2006) Karşılıklı Taklit Eğitimi’nin (KTE); (Reciprocal Imitation Training; Ingersoll, 2008a) erken dönemde OSB olan çocuklara nesne taklidi becerilerinin kazandırılması üzerindeki etkisini incelemişlerdir. Ayrıca araştırmada KTE oturumları öncesi ve sonrasında, OSB olan çocukların taklit becerilerini edinimlerinin, ortak dikkat becerileri, oyun becerileri ve dil becerileri edinimleri ile ilişsisinin belirlenmesi de amaçlanmıştır. Araştırma sonucunda, elde edilen bulgular, KTE ile sunulan taklit eğitimi sonrasında, çocukların dil, oyun ve ortak dikkat becerilerinde uygulama öncesine göre ilerlemeler olduğu görülmüştür. İlgili araştırmada, taklit becerilerinin ilerlemesi ile dil (örneğin, bağlama uygun dil kullanım düzeyi), oyun (örneğin, etkileşim içerisinde bağlama uygun nesneli oyun oynama vb. ) ve ortak dikkat becerileri (örneğin, işaret etme, gösterme vb.) gibi sosyal ve iletişim gelişimi açısından temel oluşturan becerilerin ilerlemesi arasında doğrudan bir ilişki olduğu yönünde bulgular elde edilmesinin, taklit becerilerinin sosyal işlevinin güçlendirilmesine katkı sağladığı düşünülmektedir. Bu nedenle erken dönemde OSB olan çocukların taklit becerileri profili, bu çocuklar için taklit becerilerinin öğretimi amacıyla oluşturulan müdahale programlarını ögelerinin, (taklit becerileri türleri, sergilenme biçimleri, öğretim ortamları ve bağlamları) dikkate alınmasını gerektirmektedir.

\section{Taklit Becerileri Öğretimine Yönelik Yansımalar}

OSB olan çocukların taklit becerileri alanındaki yeterlilikleri ve yetersizliklerini ortaya koymayı amaçlayan ilgili araştırmaların bulguları, bu çocuklara yönelik taklit becerileri eğitiminin şekillenmesine katkıda bulunmaktadır.

OSB olan çocuklarda taklit becerilerinin gelişimine bakıldığında, taklit becerilerinde yetersizlikler yaşadıkları, özellikle sergilenmesinde yetersizlik gözlenen taklit becerilerinin başında nesne ve jest taklidi becerilerinin geldiği görülmektedir (Stone ve ark., 1997; Ingersoll, 2008b, Rogers ve ark., 2003). Bu bağlamda, OSB semptomları belirgin düzeyde gözlenmeye başlandığında, taklit becerileri eğitimine, nesneli oyun becerilerini içeren nesne taklidi becerileri ve dil öncesi iletişim becerileri arasında yer alan jestleri içeren jest taklidi becerileri ile başlanması önerilmektedir (Ingersoll, 2008b). Ek olarak, OSB risk grubunda bulunan çocuklara yönelik erken çocukluk dönemi müdahale programlarının geliştirilmesi amacıyla geliştirilecek olan 
müdahale modeli kapsamında taklit becerileri eğitimine de yer verilmesinin, ileriki dönemlerde sosyal etkileşim ve dil gelişiminin ilerletilmesinde önemli rol oynayacağı düşünülmektedir. Bunu yanısıra ilgili araştırmalarda (Ingersoll ve Gergans, 2007; Ingersoll, 2008b, Ingersoll ve Meyer, 2011b) OSB olan çocukların taklit becerilerinin kendiliğinden sergilenmesinde ciddi düzeyde güçlük yaşadıklarının belirlenmesi nedeni ile taklit becerilerinin eğitiminde taklit eylemlerinin kendiliğinden kullanımlarının da hedeflenmesi önerilmektedir.

Alan yazın incelendiğinde taklitin öğrenme ve sosyal etkileşim işlevine sahip olduğu görülmektedir. Bu işlevlerin taklit becerileri müdahalelerine yansıması açısından, taklidin sosyal etkileşim ortamlarında gözleyerek öğrenme firsatı sunarak öğretilmesi, yeni davranışların edinimine olanak sağlamaktadır. Ek olarak, OSB olan çocuklarda taklit becerilerinin sosyal etkileşim gelişimi açısından ön koşul bir beceri durumunda olması (Ledford ve Wolery, 2011), dil ve iletişim becerileri ile ortak dikkat ve oyun gibi diğer sosyal etkileşim becerilerinin geliştirilmesinde taklit becerilerinin öğretiminin gerekliliğini ortaya koymaktadır. Bu doğrultuda erken dönemde dil ve iletişim ve diğer sosyal etkileşimsel becerilerin desteklenmesi amaciyla OSB olan çocuklara yönelik müdahalenin planlanması açısından taklidin kilit bir rol oynadığı düşünülmektedir. 


\section{KAYNAKLAR}

Amerikan Psikiyatri Birliği (2013). DSM-V-R Tanı ölçütleri başvuru kitabı. Çeviren: Ertuğrul Köroğlu. Ankara: HYB Yayıncilik.

Bandura, A. (1977). Self-efficacy: Toward a unifying theory of behavioral change. Psychological Rewiev, 84(1), $191-215$

Barr, R., Dowden, A., \& Hayne, H. (1996). Developmental changes in deferred imitation by 6- to 24-month-old infants. Infant Behavior and Development, 19(3), 159-170.

Barr, R., \& Hayne, H. (2003). It's not what you know, it's who you know: Older siblings facilitate imitation during infancy. International Journal of Early Years Education, 11(8), 7-21.

Bates, E., Bretherton, I., \& Snyder, L. (1988). From first words to grammar: Individual differences and dissociable mechanisms. New York: Cambridge University Press.

Bennetto, L. (1999). A componential approach to imitation and movement deficits in autism. Dissertation Abstracts International, 60(2-B), 0819.

Bernabei, P., Fenton, G., Fabrizi, A., Camaioni, L., \& Perucchini, P. (2003). Profiles of sensorimotor development in children with autism and with developmental delay. Perceptual and Motor Skills, 96(4), $1107-1116$.

Bernier, R., Dawson, G., Webb, S., \& Murias, M. (2007). EEG mu rhythm and imitation impairments in individuals with autism spectrum disorder. Brain and Cognition, 64(2), 228-237.

Berry, P. B. (1974). Elicited imitation and assesment of abilities. Language and Speech, 19(4), 363-373.

Browder, D., Schoen, S., \& Lentz, F. (1987). Learning to learn through observation. Journal of Special Education, 20(2), 447-462.

Brown, F. J., Peace, N., \& Parsons, R. (2009). Teaching children generalized imitation skills: A case study. Journal of Intellectual Disabilities, 13(1), 9-17.

Butterworth, G. (1999). Neonatal Imitation: Existence, Mechanisms and Motives. In J. Nadel \& G. Butterworth (Eds.). Imitation in Infancy (ss. 63-88). New York: Cambridge University Press.

Canitano, R., \& Vivanti, G. (2007). Tics and Tourette syndrome in autistic spectrum disorders. Autism, 11(4), $19-28$.

Cardon, T. (2010). Promoting imitation in young children with autism: A comparison of reciprocal imitation training and video modeling. Arizona, ABD. UMI-Dissertation Publishing by Proquest.

Carpenter, M., Nagell, K.., Tomasello, M. (1998). Social cognition, joint attention, and communicative competence from 9 to 15 months of age. Monograph of the Society for Research in Child Development, 63, Serial No. 255.

Carpenter, M., Pennington, B. E., \& Rogers, S. J. (2002). Interrelations among social-cognitive skills in young children with autism. Journal of Autism and Developmental Disorders, 32(3), 91-106.

Carpenter, M., Call, J., \& Tomasello, M. (2005). Twelve- and 18-month-olds imitate actions in terms of goals. Developmental Science, 8, F13-F20. 
Charman, T., Baron-Cohen, S., Swettenham, J., Baird, G., Drew, A., \& Cox, A. (2003). Predicting language outcome in infants with autism and pervasive developmental disorder. International Journal of Language \& Communication Disorders, 38(1), 265-285.

Charman, T., Swettenham, J., Baron-Cohen, S., Cox, A., Baird, G., and Drew, A. (1997). Infants with autism: An investigation of empathy, pretend play, joint attention, and imitation. Developmental Psychology, 33(6)781-789.

Curcio, F. (1978). Sensorimotor functioning and communication in mute autistic children. Journal of Autism and Childhood Schizophrenia, 8(3), 281-292.

Dawson, G., Meltzoff, A., Osterling, J., \& Rinaldi, J. (1998). Neuropsychological correlates of early symptoms of autism. Child Development, 69(2), 1276-1285.

Dewey, D., Cantell, M., \& Crawford, S. G. (2007). Motor and gestural performance in children with autism spectrum disorders, developmental coordination disorder, and/or attention deficit hyperactivity disorder. Journal of the International Neuropsychological Society, 13(3), 246-256.

Erjavec M., \& Horne P. J. (2008). Determinants of imitation of hand-to-body gestures in 2- and 3-year old children. Journal of the Experimental Analysis of Behavior, 89(6), 183-207.

Fiese, B. H. (1990). Playful relationships: A contextual analysis of mother-toddler interaction and symbolic play. Child Development, 61(3), 1648-1656.

Gergely, G., Bekkering, H., \& Király, I. (2002). Rational imitation in preverbal infants. Nature, 14(4), 415, 755.

Gernscbacher, M. A. (2006). Toward a behavior of reciprocity. Journal of Developmental Processes, 1(2), 139152.

Ghaziuddin, M., \& Butler, E. (1998). Clumsiness in autism and Asperger syndrome: A further report. Journal of Intellectual Disability Research, 42(4), 43-48.

Grusec, J. E., \& Abravomitch, R. (1982). Imitation of peers and adults in a natural setting: A functional analysis. Child Development, 53(3), 636-642.

Halliday S., \& Leslie J. C. (1986) A longitudinal semi-cross-sectional study of the development of mother-Child interaction. British Journal of Developmental Psychology, 4(3), 211-222.

Ham, H, S., Bartolo, A., Corley, M., Rajendran, G., Szabo, A., \& Swanson, S. (2011). Exploring the relationship between gestural recognition and imitation: Evidence of dyspraxia in autism spectrum disorders. Journal of Autism and Developmental Disorders, 41(1), 1-12.

Heimann, M., \& Meltzoff, A. N. (1996). Deferred imitation in 9- and 14-month-old infants: A longitudinal study of a Swedish sample. British Journal of Developmental Psychology, 14(2), 55-64.

Heimann, M., Ullstadius, E., Dahlgren, S. O., \& Gillberg, C. (1992). Imitation in autism: A preliminary research note. Behavioral Neurology, 5(4), 219-227.

Heimann, M., \& Ullstadius, E. (1999). Neonatal imitation and imitation among children with autism and down syndrome. In J. Nadel \& G. Butterworth (Eds.). Imitation in infancy: Progress and prospects of current research (ss. 235-253). Cambridge, United Kingdom: Cambridge University Press.

Ingersoll, B. (2008a). The effect of context on imitation skills in children with autism. Research in Autism Spectrum Disorders, 2(2), 332-340. 
Ingersoll, B. (2008b). The social role of imitation in autism: Implications for the treatment of imitation deficits. Infants \& Young Children, 21(2), 107-119.

Ingersoll, B. (2010). Brief report: Pilot randomized controlled trial of reciprocal imitation training for teaching elicited and spontaneous imitation to children with autism. Journal of Autism and Developmental Disorders, 40(9), 1154-1160.

Ingersoll, B. (2012). Brief report: Effect of a focused imitation intervention on social functioning in children with autism. Journal and of Autism Developmental Disorders, 42(8), 1768-1773.

Ingersoll, B., \& Gergans, S. (2007). The effect of a parent-implemented naturalistic imitation intervention on spontaneous imitation skills in young children with autism. Research in Developmental Disabilities, 28(2), $163-175$.

Ingersoll, B., \& Lalonde, K. (2010). The impact of nonverbal imitation training on language use in children with autism: A comparison of object and gesture imitation training. Journal of Speech, Language and Hearing Research, 53(4), 1040-1051.

Ingersoll, B., Lewis, E., \& Kroman, E. (2007) Teaching the imitation and spontaneous use of descriptive gestures in young children with autism using a naturalistic behavioral intervention, Journal and of Autism Developmental Disorders, 37(8), 1446-1456.

Ingersoll, B., \& Meyer, K. (2011a). Do object and gesture imitation skills represent independent dimensions in autism? Journal of Developmental and Physical Disabilities, 23(5), 421-431.

Ingersoll, B., \& Meyer, K. (2011b). Examination of correlates of different imitative functions in young children with autism spectrum disorders. Research in Autism Spectrum Disorders, 5(3), 1078-1085.

Ingersoll, B. \& Schreibman, L. (2006). Teaching reciprocal imitation skills to young children with autism using a naturalistic behavioral approach: Effects on language, pretend play and joint attention. Journal of Autism and Developmental Disorders, 36(4), 487-505.

Killen, M., \& Uzgiris, I. C. (1981). Imitation of actions with objects: The role of social meaning. The Journal of Genetic Psychology, 138(7), 219-229.

Landa, R. (2007). Early communication development and intervention for children with autism. Mental Retardation and Developmental Disabilities Research Reviews, 13(6), 16-25.

Ledford, J. R., \& Wolery, M. (2011). Teaching imitation to children with disabilities: A review of the literature. Topics in Early Childhood Special Education, 30(4), 245-255.

Libby, S., Powell, S., Messer, D., \& Jordan, R. (1997). Imitation of pretend play acts by children with autism and Down syndrome. Journal of Autism and Developmental Disorders, 27(2), 365-383.

Lord, C., Risi, S., Lambrecht, L., Cook, E. H., Leventhal, B. L., DiLavore, P., Pickles, A., \& Rutter, M. (2000). The autism diagnostic observation schedule-Generic: A standard measure of social and communication deficits associated with the spectrum of autism. Journal of Autism \& Developmental Disorders, 30(3), 205223.

Loveland, K. A., Tunalikotoski, B., Pearson, D. A., Brelsford, K. A., Ortegon, J., \& Chen, R. (1994). Imitation and expression of facial affect in autism. Development and Psychopathology, 6(3), 433-444.

Luyster, R., Kadlec, M. B., Connolly, C., Carter, A., \& Tager-Flusberg, H. (2008). Language assessment and development in toddlers with autism spectrum disorders. Journal of Autism and Developmental Disorders, 38(8), 1426-1438. 
Masur, F. E., \& Olson, J. (2008). Mothers' and infants' responses to their partners' spontaneous action and vocal/verbal imitation. Infant Behavior \& Development, 31(4), 704-715.

McCabe, M., \& Uzgiris, I. C. (1983). Effects of model and action on imitation in infancy. Merrill-Palmer Quarterly, 29(2), 69-82.

McDuffie, A., Turner, L., Stone, W., Yoder, P., Wolery, M., \& Ulman, T. (2007). Developmental correlates of different types of motor imitation in young children with autism spectrum disorders, Journal of Autism and Developmental Disorders, 37(3), 401-412.

Meltzoff, A. N. (1988). Infant imitation after a I-week delay: Long-term memory for novel acts and multiple stimuli. Developmental Psychology, 24(4), 470-476.

Meltzoff, A. N. (1993). The centrality of motor coordination and proprioception in social and cognitive development: From shared actions to shared mind. In G.J.P. Savelsbergh (Ed.). The development of coordination in infancy (ss. 463-496). Amsterdam, The Netherlands: Free University Press.

Meltzoff, A. N. (1999). Origins of theory mind, cognition, and communication. Journal of Communication Disorders, 32(1999), 251-269.

Meltzoff, A. N., \& Moore, M. K. (1989). Imitation in newborn infants: Exploring the range of gestures imitated and the underlying mechanisms. Developmental Psychology, 25(6), 954-962.

Meltzoff, A. N., \& Moore, M. K. (1992). Early imitation within a functional framework: The importance of person identity, movement, and development. Infant Behavior \& Development, 15(1), 479-505.

Nadel, J. (2006). Does imitation matter to children with autism? In S. Rogers \& J. Williams (Eds.), Imitation and the social mind (ss. 118-137). NY: The Guilford Press.

Nadel, J., Guérini, C., Pezé, A., \& Rivet, C. (1999). The evolving nature of imitation as a transitory means of communication. In J. Nadel \& G. Butterworth (Eds.). Imitation in infancy (ss. 209-234). Cambridge, UK: Cambridge University Press.

Ohta, M. (1987). Cognitive disorders of infantile autism: A study employing the WISC, spatial relationship, conceptualization, and gestural imitation. Journal of Autism and Developmental Disorders, 17(1), 45-62.

Paavola, L. (2006). Maternal Sensitive Responsiveness, Characteristics and Relations to Child Early Communicative and Linguistic Development. Oulu, Finland. UMI-Dissertation Publishing by Proquest.

Poulson, L. C., Kyparissos, N., Andreatos, M., Kymissis, E., \& Parnes, M. (2002). Generalized imitation within three response classesin typically developing infants. Journal of Experimental Child Psychology, 81(3), 341-357.

Rodgon, M. M., \& Kurdek, L. A. (1977). Vocal and gestural imitation in 8-, 14-, and 20-month-old children. The Journal of Genetic Psychology, 131(1), 115-123.

Rogers, S. J., Bennetto, L., McEvoy, R., \& Pennington, B. F. (1996). Imitation and pantomime in highfunctioning adolescents with autism spectrum disorders. Child Development, 67(9), 2060-2073.

Rogers, S. J, Hepburn, S. L., Stackhouse, T., \& Wehner, E.A. (2003). Imitation performance in toddlers with autism and those with other developmental disorders. Journal of Child Psychology and Psychiatry, 44(5), 763-781.

Rogers, S. J., \& Pennington, B. F. (1991). A theoretical approach to the deficits in infantile autism. Development and Psychopathology, 3(2), 137-162. 
Rogers, S. J., Young, G. S., Cook, I., Giolzetti, A., \& Ozonoff, S. (2008). Deferred and immediate imitation in regressive and early onset autism. Journal of Child Psychology and Psychiatry, 49(4), 449-457.

Salowitz, N. M. G., Eccarius, P., Karst, J., Carson, A., Schohl, K., Stevens, S., Van Hecke, V. A., \& Scheidt, A. R. (2013). Brief report: Visual-spatial guidance of movement during gesture movement and mirror drawing in children with autism spectrum disorders. Journal of Autism and Developmental Disorders; 43(4), 985995.

Sakkalou, E., Ellis-Davies, K., Fowler, C. N., Hilbrink, E. E., \& Gattis, M. (2013). Infants show stability of goaldirected imitation. Journal of Experimental Child Psychology, 114(1), 1-9.

Seehagen, S., \& Herbert, S. J. (2012). Selective imitation in 6-month-olds: The role of the social and physical context. Journal of Experimental Child Psychology, 35(3), 509-512.

Smith, I., \& Bryson, S. (1994). Imitation and action in autism: A critical review. Psychological Bulletin, 116(2), 259-273.

Stone, W. L., \& Lemanek, K. L. (1990). Parental report of social behaviors in autistic preschoolers. Journal of Autism and Developmental Disorders, 20(4), 513-522.

Stone, W. L., Ousley, O. Y., \& Littleford, C. D. (1997). Motor imitation in young children with autism: What's the object? Journal of Abnormal Child Psychology, 25(6), 475-485.

Stone, W. L., \& Yoder, P. J. (2001). Predicting spoken language level in children with autism spectrum disorders. Autism, 5(4), 341-361.

Subiaul F., Lurie H., Romansky K., Klein T., Holmes D., \& Terrace H. S. (2007). Cognitive imitation in typically-developing 3- and 4-year olds and individuals with autism. Cognitive. Develeopment, 22(2), 230243.

Toth, K., Munson, J., Meltzoff, A. N., \& Dawson, G. (2006). Early predictors of communication development in young children with autism spectrum disorder: joint attention, imitation, and toy play. Journal of Autism and Developmental Disorders, 36(8), 993-1005.

Turan, F., \& Ökçün-Akçamuş, M. Ç. (2013). Otistik spektrum bozukluğu olan çocuklarda taklit becerileri ve taklidin alıcı-ifade edici dil gelişimi ile ilişkilerinin incelenmesi. Türk Psikiyatri Dergisi, 24(2), 111-116.

Uzgiris, I. (1990). The social context of infant imitation. In M. Lewis \& S. Feinman (Eds.). Social influences and socialization in infancy (ss. 215-251). New York: Plenum Press.

Uzgiris, I. C. (1999). Imitation as activity: its developmental aspects. In Nadel, J. and Butterworth, G., (Eds.). Imitation in infancy, (ss.187-206).

Vanvuchelen, M., Roeyers, H., \& De Weerdt, W. (2010). Imitation assessment and its utility to the diagnosis of autism: Evidence from consecutively clinical preschool referrals for suspected autism, Journal of Autism and Developmental Disorders, $41(4), 484-496$.

Vanvuchelen, M., Roeyers, H., \& De Weerdt, W. (2011). Do imitation problems reflect a core characteristic in autism?: Evidence from a literature review. Research in Autism Spectrum Disorders, 5(1), 89-95.

Vivanti, G., Nadig, A., Ozonoff, S., \& Rogers, S. J. (2008). What do children with autism attend to during imitation tasks? Journal of Experimental Child Psychology, 101(3), 186-205.

Walton, K., \& Ingersoll, B. (2012). Evaluation of a sibling-mediated imitation intervention for young children with autism. Journal of Positive Behavior Interventions, 14(4), 241-253. 
Wieland, A., \& Stephan, W. (1978). The Effects of race on imitation. The Journal of Genetic Psychology, 133(2), 277-285.

Williams, J. H. G., Waiter, G. D., Gilchrist, A., Perrett, D. I., Murray, A. D., \& Whiten, A. (2006). Neural mechanisms of imitation and 'mirror neuron' functioning in autistic spectrum disorder. Neuropsychologia, 44(4), 610-621.

Zachor, D. A., Ilanit, T., \& Itzchak, E. B. (2010). Autism severity and motor abilities correlates of imitation situations in children with autism spectrum disorders. Research in Autism Spectrum Disorders, 4(3), 438443.

Zaghlawan, H. (2010). A parent-implemented intervention to improve spontaneous imitation by young children with autism. Urbana, Illinois, ABD. UMI-Dissertation Publishing by Proquest.

Zmyj, N., Daum, M. M., \& Aschersleben, G. (2009). The development of rational imitation in 9- and 12-monthold infants. Infancy, 14(1), 131-141.

Zmyj, N., Buttelmann, D., Carpenter, M. J., \& Daum, M. M. (2010). The reliability of a model influences 14month-olds' imitation. Journal of Experimental Child Psychology, 106(4), 208-220. 


\section{Summary}

\section{Imitation Skills of Children with Autism Spectrum Disorders in Early Childhood}

\author{
Gökhan Töret* \\ Gazi University
}

\author{
E. Rüya Özmen** \\ Gazi University
}

With a rapid increase in the research studies which targeted imitation skills of children with autism spectrum disorders (ASD) in early childhood, the important role of the imitation skills on development of language, communication and social interaction skills has been more frequently emphasized. In this study, the purpose was to examine the imitation skills of children with ASD who exhibit specific language, communication and social interaction deficits (Landa, 2007).

The most common definition of imitation is to eagerly reproduce a behavior pattern which has been exhibited by somebody else (Butterworth, 1999). Imitation skills are differently classified in the literature. Different categories of imitation skills are based on the body parts which the imitation is exhibited, duration of imitation, function of imitation to learn new skills and behaviors and learning functions of imitation. Imitation has communicative, social, and learning functions.

For children with typical development imitation begins with the birth. During sixth to ninth months children begin to imitate with objects, vocalizations preceding structured imitation actions followed by unstructured imitation actions, meaningless imitation actions followed by meaningful imitation actions (Zmyj et al., 2010). When children reach 36 months of age another important stage in the development of imitation is achieved with the spontaneous use of imitation skills in natural play settings (Meltzoff, 1988; Nadel, 2006).

This developmental process in typically developing children is limited in terms of type and frequency and follows an unusual pattern for children with ASD. Several studies show that children with ASD have more limited imitation skills than their peers with typical development (Charman et al., 1997; Curcio, 1978; Dawson, Meltzoff, Osterling, \& Rinaldi, 1998; Heimann, Ullstadius, Dahlgren, \& Gillberg, 1992; Ingersoll, 2008; Libby, Powel, Messer, \& Jordan, 1997; Rogers et al., 2003; Rogers \& Pennigton, 1991; Smith \& Bryson, 1994; Stone et al., 1997; Turan \& Ökçün-Akçamuş, 2013). Studies also show that children with ASD have deficiency in spontaneous and delayed imitation skills (Dawson, Meltzoff, Osterling, \& Rinaldi, 1998), imitating facial expressions (Loveland et al., 1994), imitating with and without objects (Stone et al., 1997; Turan \& ÖkçünAkçamuş, 2013), imitating gestures (Curcio, 1978; Smith \& Byrson, 1994; Stone et al., 1997), and imitating

\footnotetext{
* Research Asisstant, Gazi University, Gazi Faculty of Education, Department of Special Education, Ankara, E-mail: gokhantoret@hotmail.com

*** Prof. Dr., Gazi University, Gazi Faculty of Education, Department of Special Education, Ankara, E-mail: eruya@gazi.edu.tr
} 
symbolic actions (Libby et al., 1997). As a result, children with ASD are found to be more competent in nongesture action imitations including hand or arm movements which are motor imitations (e.g., tapping both hands on the table) than gesture imitations (Stone et al., 1997), in meaningful gesture skills than meaningless gesture imitations (Stone et al., 1997; Salowitz et al., 2013), and in structured imitation skills than spontaneous imitation skills.

As for children with typical development imitation plays a crucial role in the development of cognitive, social and communicative skills of children with ASD (Ingersoll, 2008a). Imitation in children with ASD is related with language (Bates, Bretherton, \& Snyder, 1988), play (Fiese, 1990), and joint attention (Carpenter, Nagell \& Tomasello, 1998). Studies conducted with children with ASD show that imitation is simultaneously related with language (Carpenter, Pennigton, \& Rogers, 2002; Charman et al., 2003; Luyster, Kadlec, Carter, \& Tager-Flusberg, 2008; Stone, Ousley, \& Littleford, 1997; Toth, Munson, Meltzoff, \& Dawson, 2006; Turan \& Ökçün-Akçamuş, 2013) and play skills (Stone et al., 1997; Toth et al., 2006). In the study of examining the relationship between imitation and pre-linguistic communication skills Curcia (1978) found that gesture imitation was correlated with the number of communicative gestures of children with autism who did not have any verbal communication. Therefore it is suggested in teaching imitation skills to children with ASD a) to begin with teaching imitation with objects which includes playing with objects, and gesture imitation skills which are included in pre-linguistic communication skills when the symptoms of ASD start to become apparent (Ingersoll, 2008a), b) beginning from early stages to teach play actions with objects which allow for developing play routines (feeding a teddy bear, catching fish with fishing net) and which are related in terms of social interactive context, language, and communication (Ingersoll \& Meyer, 2011a) and to teach gesture imitation which plays a crucial role in the development of play actions with objects and pre-linguistic communication (pointing an object, showing an object by holding it up or turning hands up to ask for where the object is) (Ingersoll, 2008), c) since children with ASD show significant difficulties in spontaneously exhibiting imitation skills (Ingersoll \& Gergans, 2007; Ingersoll, 2008b, Ingersoll \& Meyer, 2011b) to teach spontaneous use of imitation, and d) to teach imitation in play contexts in line with the nature of responsiveness which makes social interaction possible. 